\title{
Bioaccumulative Characteristics of Polybrominated Diphenyl Ethers in Channel Catfish and Fish Feeds from China
}

\author{
Xiaozhong $\mathrm{Hu}^{1 * \#, ~ D e c o n g ~} \mathrm{Hu}^{1 * \#, ~ B i n ~} \mathrm{Wu}^{2}$, Changjun Lin ${ }^{2}$ \\ ${ }^{1}$ Technology Center of Hubei Entry-Exit Inspection and Quarantine Bureau of PRC, Wuhan, China \\ ${ }^{2}$ Technology Center of Liaoning Entry-Exit Inspection and Quarantine Bureau of PRC, Dalian, China \\ Email: ${ }^{*}$ huxz2002@163.com, ${ }^{*}$ deconghu hust@163.com
}

Received 19 June 2014; revised 15 July 2014; accepted 4 August 2014

Copyright (C) 2014 by authors and Scientific Research Publishing Inc.

This work is licensed under the Creative Commons Attribution International License (CC BY). http://creativecommons.org/licenses/by/4.0/

(c) (i) Open Access

\section{Abstract}

PBDEs are widely used brominated flame retardant, which are increasingly reported in the environment. Concentrations of thirteen PBDEs in a large number of channel catfish and fish feeds collected from Hubei province of China were investigated in this study. A fast isotopic dilution GC-MS method was firstly developed to simultaneously determine thirteen PBDEs in channel catfish and fish feeds in this study, and especially for the first time PBDEs in fish feeds. Pressurized liquid extraction and multi-layer silica gel column chromatography cleanup were used, some important steps and crucial parameters were modified and intensified compared with other literatures, and GC and MS conditions were optimized. The limits of quantitation values of 0.25 - 5 $\mu \mathrm{\mu} \cdot \mathrm{kg}^{-1}$ wet weight in channel catfish were calculated for PBDEs; so did 1 - $20 \mu \mathrm{g} \mathrm{kg}^{-1}$ wet weight in fish feeds. In addition, good repeatability and accuracy of the whole method were achieved. The established methods were therefore suitable for the simultaneous determinations of thirteen PBDEs in these samples at trace contamination levels. Using the established methods, PBDEs emerged in 10 of 180 channel catfish and 13 of 115 fish feeds, and the dominant PBDEs homologues were PBDE-28, PBDE-47, PBDE-100, PBDE-99, PBDE-154, PBDE-153 and PBDE-183. The detection rates of seven PBDEs congeners were in turn respectively $1.74 \%, 7.83 \%, 4.35 \%, 5.22 \%$, $3.48 \%, 2.61 \%$ and $2.61 \%$ in fish feeds, and detection rates of seven PBDEs congeners were in turn respectively $1.11 \%, 3.89 \%, 2.22 \%, 1.67 \%, 1.11 \%, 1.11 \%$ and $1.11 \%$ in channel catfish. There was significant correlation in PBDEs between matching channel catfish and fish feeds $\left(R^{2}=0.742, P<\right.$ $0.001, n=30$ ), suggesting that fish feeds contaminated with PBDEs possibly resulted in PBDEs residual in channel catfish through biological transfer.

\footnotetext{
"Corresponding author.

"Decong Hu and Xiaozhong Hu contribute equally to this work and are both as the first author.
}

How to cite this paper: Hu, X.Z., Hu, D.C., Wu, B. and Lin, C.J. (2014) Bioaccumulative Characteristics of Polybrominated Diphenyl Ethers in Channel Catfish and Fish Feeds from China. Journal of Environmental Protection, 5, 936-948. 


\section{Keywords}

\section{Polybrominated Diphenyl Ethers (PBDEs), Channel Catfish, Fish Feeds, Bioaccumulative Characteristics, GC-MS}

\section{Introduction}

Polybrominated diphenyl ethers (PBDEs) are one class of halogenated organic brominated flame retardants (BFRs), and have been used industrially in large volumes for flame protection purposes in various commercial products such as electronic equipment and textiles. The commercial PBDEs products predominantly consist of so-called penta-, octa- and decabromodiphenyl ether products. Because of their physical, chemical and bio-accumulative characteristics, such as environmental persistence and high lipophilicity, these products have been widely distributed in the environment, for example air, dust, bird eggs, fish, marine mammals and human milk, where they are found to persist for a long time [1]-[10].

Following concerns about contamination status of PBDEs in the environment, the rising attentions were led about the possible adverse health effects to humans. Toxicity studies indicate that the liver, thyroid gland and possibly developing reproductive organs are particular targets of PBDEs toxicity [11] [12]. More and more evidences are emerging that PBDEs may be developmental neurotoxicants, as behavioural, neurochemical and hormonal deficits have been found following perinatal exposure [13]-[18]. PBDEs are capable to induce cell death of cerebellar granule cells in culture [19]. Madia et al. reports PBDE-99 can induce apoptosis in astrocytoma cells assessed by the TUNEL method and by Hoechst 33258 staining, via a p53 dependent mechanism [20]. Our study indicates PBDE-209 and PBDE-47 can inhibit the proliferation of Hep G2 cells by inducing apoptosis through ROS or NO generation [21] [22]. To satisfy the requirements of further accurate risk assessments for these chemicals, it is expected that the trend in generating PBDEs data will be encouraged to grow in environmental and biotic samples, especially in farm and aquaculture products.

The Hubei province of China has an old farm and aquaculture production tradition. Especially there are a plenty of channel catfish from Hubei exported to other countries. These productions are favorite food for people and their safety has been highly concerned by our previous papers [23] [24]. Moreover, fish feeds are one kind of farm products, their contaminations have also been concerned in our previous papers as contaminated animal feeds can cause deleterious health effects in the animals and, through "secondary exposure" of consumers to products deriving from these animals, may be harmful to human health [24] [25]. To our knowledge, there is little information about the degree of PBDEs contamination in channel catfish and fish feeds from the region in China. The analysis of PBDEs in biological samples is difficult because they are usually present at $\mu \mathrm{g} \cdot \mathrm{kg}^{-1} \mathrm{le}-$ vels and the matrices involved are generally complex. Therefore, highly selective and sensitive techniques including sample preparation, cleanup, instrument and quantitative method are required.

The present work is to describe a simultaneous determinations of thirteen PBDEs in channel catfish and fish feeds by isotopic dilution GC-MS which is always more reliable and especially for the first time for determinations of PBDEs in fish feeds. In addition, the contamination of PBDEs in these samples matrix from the Hubei province of China will be investigated and the correlation in PBDEs between matching channel catfish and fish feeds will be studied.

\section{Material and Methods}

\subsection{Chemicals and Reagents}

Acetone was supplied from J.T. Baker (Phillipsburg, USA). Cyclohexane, dichloromethane (DCM) and iso-octane were supplied from CNW (Germany). Anhydrous sodium sulfate $\left(\mathrm{Na}_{2} \mathrm{SO}_{4}\right)$ (p.a.) was from Sinopharm Chemical Reagent Co., Ltd. (Shanghai, China). Florisil was from Sigma-Aldrich Laborchemikalien GmbH (Seelze, Germany). Silica gel 60 (0.063 - 0.200 mm, 70 - 230 mesh ASTM) was from Merck (Darmstadt, Germany).

A standard solution of native PBDEs containing congeners BDE17, BDE28, BDE47, BDE66, BDE71, BDE85, BDE99, BDE100, BDE138, BDE153, BDE154, BDE183 and BDE190, at $5 \mu \mathrm{g} \cdot \mathrm{mL}^{-1}$ of each congener 
in iso-octane and toluene (97.5:2.5), was also obtained from AccuStandard, Inc. (USA). For quantification by isotope dilution and internal standard, a standard mixture of ${ }^{13} \mathrm{C}_{12}$-labelled PBDEs 28, 47, 99, 100, 154, 153 and 183 (MBDE-MXFS), supplied by Wellington Laboratories, at $2 \mu \mathrm{g} \cdot \mathrm{mL}^{-1}$ of each congener in toluene and nonane (74.8:25.2) was used as surrogate internal standard. In addition, a standard mixture of ${ }^{13} \mathrm{C}_{12}$-BDE77 and 138 (MBDE-MXFR) at a concentration of $2 \mu \mathrm{g} \cdot \mathrm{mL}^{-1}$ in toluene and nonane (92.8:7.2) (Wellington Laboratories) was used as syringe standard for recovery determination. Mixed series working standards of PBDEs containing MBDE-MXFS and MBDE-MXFR were prepared by serial dilutions of these stock solutions with iso-octane. The detailed information of these standard substances was presented in Table 1.

\subsection{Channel Catfish and Fish Feeds Samples}

In the first stage, eighty commercial channel catfish and sixty fish feeds respectively collected from local markets in the Hubei province of China, were used in the present study from August to November, 2013. In the second stage, one hundred commercial channel catfish and fifty fish feeds respectively collected from local markets in the Hubei province of China, were used from March to June, 2014. Muscle tissues of channel catfish were collected and homogenized. Fish feeds were filtered through a US 20 mesh screen to ensure the samples uniformity.

\subsection{Determination of PBDEs}

Analysis of PBDEs in channel catfish and fish feeds was prepared by using a literature method and an ISO me-

Table 1. The information and the ions monitored of thirteen PBDEs, MBDE-MXFS and MBDE-MXFR.

\begin{tabular}{|c|c|c|c|c|c|c|}
\hline Br No. & Abbreviation & Molar mass & $\begin{array}{l}\text { Precursor ions, }[\mathrm{M}]^{+} \\
\text {and }[\mathrm{M}+2]^{+} \text {, or } \\
{[\mathrm{M}-2]^{+}(\mathrm{m} / \mathrm{z})}\end{array}$ & $\begin{array}{c}\text { Product ions, } \\
{[\mathrm{M}-2 \mathrm{Br}]^{+} \text {and }[(\mathrm{M}+2)-2 \mathrm{Br}]^{+} \text {, or }} \\
{[(\mathrm{M}-2)-2 \mathrm{Br}]^{+}(\mathrm{m} / \mathrm{z})}\end{array}$ & $\begin{array}{l}\text { The ions monitored } \\
\qquad(\mathrm{m} / \mathrm{z})\end{array}$ & $\begin{array}{l}\text { No. of MS Scan } \\
\text { Functions }\end{array}$ \\
\hline \multicolumn{7}{|c|}{ PBDEs } \\
\hline 3 & BDE17 & 407 & 406, $[\mathrm{M}+2]^{+}$ & 246,248 & $406,408, \underline{246}, 248$ & 2 \\
\hline 3 & BDE28 & 407 & 406, $[\mathrm{M}+2]^{+}$ & 246, 248 & $406,408, \underline{246}, 248$ & 4 \\
\hline 4 & BDE71 & 486 & 486, $[\mathrm{M}-2]^{+}$ & 326,328 & $484,486, \underline{326}, 328$ & 5 \\
\hline 4 & BDE47 & 486 & 486, $[\mathrm{M}-2]^{+}$ & 326, 328 & $484,486, \underline{326}, 328$ & 6 \\
\hline 4 & BDE66 & 486 & 486, $[\mathrm{M}-2]^{+}$ & 326,328 & $484,486, \underline{326}, 328$ & 8 \\
\hline 5 & BDE100 & 565 & $564,[\mathrm{M}+2]^{+}$ & 404,406 & $564,566, \underline{404}, 406$ & 11 \\
\hline 5 & BDE99 & 565 & $564,[\mathrm{M}+2]^{+}$ & 404,406 & $564,566, \underline{404}, 406$ & 13 \\
\hline 5 & BDE85 & 565 & $564,[\mathrm{M}+2]^{+}$ & 404,406 & $564,566, \underline{404}, 406$ & 14 \\
\hline 6 & BDE154 & 644 & $644,[\mathrm{M}-2]^{+}$ & 484,486 & $642,644, \underline{484}, 486$ & 16 \\
\hline 6 & BDE153 & 644 & $644,[\mathrm{M}-2]^{+}$ & 484,486 & $642,644, \underline{484}, 486$ & 18 \\
\hline 6 & BDE138 & 644 & $644,[\mathrm{M}-2]^{+}$ & 484,486 & $642,644, \underline{484}, 486$ & 20 \\
\hline 7 & BDE183 & 723 & $722,[\mathrm{M}+2]^{+}$ & 562,564 & $722,724,562, \underline{564}$ & 22 \\
\hline 7 & BDE190 & 723 & $722,[\mathrm{M}+2]^{+}$ & 562,564 & $722,724,562, \underline{564}$ & 23 \\
\hline \multicolumn{7}{|c|}{ MBDE-MXFS } \\
\hline 3 & ${ }^{13} \mathrm{C}_{12}-\mathrm{BDE}-28$ & 419 & $418,[\mathrm{M}+2]^{+}$ & 258,260 & $418,420, \underline{258}, 260$ & 3 \\
\hline 4 & ${ }^{13} \mathrm{C}_{12}-\mathrm{BDE}-47$ & 500 & $498,[\mathrm{M}+2]^{+}$ & 338,340 & $498,500, \underline{338}, 340$ & 7 \\
\hline 5 & ${ }^{13} \mathrm{C}_{12}-\mathrm{BDE}-100$ & 577 & $576,[\mathrm{M}+2]^{+}$ & 416,418 & $576,578, \underline{416}, 418$ & 10 \\
\hline 5 & ${ }^{13} \mathrm{C}_{12}-\mathrm{BDE}-99$ & 577 & $576,[\mathrm{M}+2]^{+}$ & 416,418 & $576,578, \underline{416}, 418$ & 12 \\
\hline 6 & ${ }^{13} \mathrm{C}_{12}-\mathrm{BDE}-154$ & 656 & $656,[\mathrm{M}-2]^{+}$ & 494, 496 & $654,656, \underline{496}, 498$ & 15 \\
\hline 6 & ${ }^{13} \mathrm{C}_{12}-\mathrm{BDE}-153$ & 656 & $656,[\mathrm{M}+2]^{+}$ & 494, 496 & $656,658,494, \underline{496}$ & 17 \\
\hline 7 & ${ }^{13} \mathrm{C}_{12}-\mathrm{BDE}-183$ & 735 & $734,[\mathrm{M}+2]^{+}$ & 574,576 & $734,736, \underline{574}, 576$ & 21 \\
\hline \multicolumn{7}{|c|}{ MBDE-MXFR } \\
\hline 4 & ${ }^{13} \mathrm{C}_{12}-\mathrm{BDE}-77$ & 500 & 498, $[\mathrm{M}+2]^{+}$ & 338,340 & $\underline{498}, 500,336,338$ & 9 \\
\hline 6 & ${ }^{13} \mathrm{C}_{12}-\mathrm{BDE}-138$ & 656 & $656,[\mathrm{M}+2]^{+}$ & 494,496 & $656,658, \underline{496}, 498$ & 19 \\
\hline
\end{tabular}

The ion of underline was indicated for quantitative analysis. 
thod modified [26] [27]. The ASE 200 (DIONEX, USA) was used for the pressurized liquid extraction (PLE) experiments. Ten gram of muscle tissue of channel catfish, and $2.5 \mathrm{~g}$ of fish feeds were homogenized with Florisil at a proportion of $1 / 2(\mathrm{w} / \mathrm{w})$ after adding $1 \mathrm{~mL}$ of surrogate internal standard solution (the concentrations of ${ }^{13} \mathrm{C}_{12}$-labelled PBDEs 28, 47, 99, 100, 154, 153 and 183 were $100 \mathrm{ng} \cdot \mathrm{mL}^{-1}$ ) were placed in an extraction cell. DCM-acetone (1:1, v/v) was used as extraction solvent. The system pressure was set at $1500 \mathrm{psi}$ and the temperature at $100^{\circ} \mathrm{C}(100 \%$ flush volume) with a heat-up time of $6 \mathrm{~min}$. Three cycles of extraction were performed during $5 \mathrm{~min}$ in static mode and the purge time was set at $90 \mathrm{~s}$. The extracts of two kinds of samples were then concentrated and for further cleanup according to the following method.

The above total extracts of two kinds of samples were firstly concentrated approximately $1 \mathrm{~mL}$ using iso-octane as the keeper at $40^{\circ} \mathrm{C}$ in a water bath by a K-D vacuum rotary concentrator, and $5.0 \mathrm{~mL}$ of iso-octane was added to dissolve the residue. Then the residue was transferred to a glass tube, and concentrated about $2 \mathrm{~mL}$ by a gentle stream of nitrogen. The resulting mixture was filtrated with a $0.22 \mu \mathrm{m}$ membrane for next cleanup. Cleanup procedure was performed according to the ISO method modified [27]. The extract was subjected to multi-layer silica column chromatography for the removals of acid compounds, basic compounds, sulfur and sulfur-containing molecules and small amounts of water. The silica column $(22 \mathrm{~mm}$ i.d. $\times 20 \mathrm{~cm})$ was packed in the following sequence: $2 \mathrm{~g}$ of silica, $5 \mathrm{~g}$ of $34 \% \mathrm{NaOH}$ silica, $2 \mathrm{~g}$ of silica, $10 \mathrm{~g} 44 \% \mathrm{H}_{2} \mathrm{SO}_{4}$ silica, $2 \mathrm{~g}$ of silica, $5 \mathrm{~g}$ of $10 \% \mathrm{AgNO}_{3}$ silica and $10 \mathrm{~g}$ of $\mathrm{Na}_{2} \mathrm{SO}_{4}$. The column was firstly conditioned with $50 \mathrm{~mL}$ of DCM, and then conditioned with $50 \mathrm{~mL}$ of cyclohexane. The above extract was transferred to the column. For elution, 50 $\mathrm{mL}$ of cyclohexane was used, and followed by $50 \mathrm{~mL}$ of cyclohexane: DCM (1:1). The flow rate was $2.5 \mathrm{~mL} \cdot \mathrm{min}^{-1}$. The $100 \mathrm{~mL}$ eluates were combined and concentrated approximately $1 \mathrm{~mL}$ using iso-octane as the keeper at $40^{\circ} \mathrm{C}$ in a water bath by a $\mathrm{K}-\mathrm{D}$ vacuum rotary concentrator, and $5.0 \mathrm{~mL}$ of iso-octane was added to dissolve the residue. Then the residue was transferred to a glass tube, and concentrated almost to dryness by a gentle stream of nitrogen. Zero point nine five milliliter of iso-octane followed by $0.05 \mathrm{~mL}$ syringe standard solution (the concentrations of ${ }^{13} \mathrm{C}_{12}$-BDE77 and 138 were $2 \mu \mathrm{g} \cdot \mathrm{mL}^{-1}$ ) were added to dissolve the residue and transferred to an injection vial prior to GC-MS analysis. Sample blanks were taken through all aspects of the experimental procedure.

\subsection{GC-MS}

A PE Clarus 600 GC-MS with electron impact ionization (EI) was used to the simultaneous determinations of thirteen PBDEs. An Elite-5MS column ( $30 \mathrm{~m} \times 0.25 \mathrm{~mm}$ (id), $0.25 \mu \mathrm{m}$ film thickness; perkinelmer, USA), was used to separate thirteen PBDEs, seven labeled PBDEs (surrogate internal standard) and other two labeled PBDEs (syringe standard). The oven temperature was programmed from $100^{\circ} \mathrm{C}$ (held for $1 \mathrm{~min}$ ) to $200^{\circ} \mathrm{C}$ at $20^{\circ} \mathrm{C} \cdot \mathrm{min}^{-1}$ and then to $280^{\circ} \mathrm{C}$ at $2.5^{\circ} \mathrm{C} \cdot \mathrm{min}^{-1}$ and finally to $320^{\circ} \mathrm{C}$ at $5^{\circ} \mathrm{C} \cdot \mathrm{min}^{-1}$ (held for $10 \mathrm{~min}$ ). The total runtime was $56 \mathrm{~min}$. Helium was used as carrier gas at a constant flow rate of $1 \mathrm{~mL} \cdot \mathrm{min}^{-1} .2 .5$ microliter of samples and standards were injected in splitless injection mode at an injector temperature of $275^{\circ} \mathrm{C}$. The information of retention times (RT), start time and end time of retention window, No. of MS scan functions and quantitation reference for PBDEs, MBDE-MXFS and MBDE-MXFR on Elite-5MS were presented in Table 2.

MS operating conditions were the following: electron ionization mode using automatic gain control (AGC) with electron energy of $70 \mathrm{eV}$ and an emission current of $250 \mu \mathrm{A}$. The transfer line and ion source temperatures were kept at $320^{\circ} \mathrm{C}$ and $250^{\circ} \mathrm{C}$, respectively. The electron multiplier voltage was set to $370 \mathrm{~V}$.

Quantitative determination by GC-MS (EI+) was in the selected ion monitoring (SIM) mode. The ions monitored for PBDEs, including labeled PBDEs were presented in Table 1.

\subsection{Quantification and Quality Control}

Our laboratory has established a quality assurance system as per ISO/IEC 17025: 2005 for strict controls over personnel, conditions of instruments, experimental situation, etc. Thirteen PBDEs were quantified by isotope dilution or internal standard using seven surrogate internal standards, and the quantification of real samples was dealt with by isotope dilution or internal standard in this study. On the one hand, isotope dilution was used for calibration of PBDEs that have a labeled analog, for example, for calibration of BDE28, on the other hand, internal standard was applied to determination of PBDEs for which a labeled analog was not used in the study. The detailed information of quantitation reference for thirteen PBDEs was given in Table 2 .

In order to ensure the accuracy of the results and the applicability of the method in the study, in the case of 
Table 2. Retention times (RT), start time and end time of retention window, No. of MS scan functions, quantitation reference for PBDEs, MBDE-MXFS and MBDE-MXFR on Elite-5MS, and LOQ of PBDEs in channel catfish and fish feeds.

\begin{tabular}{|c|c|c|c|c|c|c|c|}
\hline \multirow[b]{2}{*}{ Br No. } & \multirow[b]{2}{*}{ Compounds } & \multirow[b]{2}{*}{ Quantitation reference } & \multirow{2}{*}{$\begin{array}{l}\text { Retention } \\
\text { times (RT) } \\
\text { (min) }\end{array}$} & \multirow{2}{*}{$\begin{array}{l}\text { Start time and end } \\
\text { time of Retention } \\
\text { Window (min) }\end{array}$} & \multirow{2}{*}{$\begin{array}{l}\text { No. of MS } \\
\text { Scan } \\
\text { Functions }\end{array}$} & \multicolumn{2}{|c|}{ LOQ } \\
\hline & & & & & & $\begin{array}{l}\text { Channel catfish } \\
\left(\mu \mathrm{g} \cdot \mathrm{kg}^{-1}\right)\end{array}$ & $\begin{array}{l}\text { Fish feeds } \\
\left(\mu \mathrm{g} \cdot \mathrm{kg}^{-1}\right)\end{array}$ \\
\hline \multicolumn{8}{|c|}{ Compounds using ${ }^{13} \mathrm{C}_{12}$-BDE-77 as Labeled injection internal standard } \\
\hline 3 & BDE17 & ${ }^{13} \mathrm{C}_{12}-\mathrm{BDE}-28$ & 14.11 & $13.44-14.53$ & 2 & 0.25 & 1 \\
\hline 3 & BDE28 & ${ }^{13} \mathrm{C}_{12}$-BDE-28 & 14.92 & $14.24-15.40$ & 4 & 0.25 & 1 \\
\hline 4 & BDE71 & ${ }^{13} \mathrm{C}_{12}$-BDE-47 & 19.69 & $18.93-20.05$ & 5 & 0.5 & 2 \\
\hline 4 & BDE47 & ${ }^{13} \mathrm{C}_{12}$-BDE-47 & 20.37 & $19.66-20.87$ & 6 & 0.5 & 2 \\
\hline 4 & BDE66 & ${ }^{13} \mathrm{C}_{12}-\mathrm{BDE}-47$ & 21.36 & $20.64-21.88$ & 8 & 0.5 & 2 \\
\hline 5 & BDE100 & ${ }^{13} \mathrm{C}_{12}-\mathrm{BDE}-100$ & 25.06 & $24.27-25.55$ & 11 & 1 & 4 \\
\hline 5 & BDE99 & ${ }^{13} \mathrm{C}_{12}$-BDE-99 & 26.68 & $25.96-27.05$ & 13 & 1 & 4 \\
\hline 5 & BDE85 & ${ }^{13} \mathrm{C}_{12}$-BDE-99 & 29.35 & 28.61 - 29.88 & 14 & 1 & 4 \\
\hline \multicolumn{8}{|c|}{ Compounds using ${ }^{13} \mathrm{C}_{12}$-BDE-138 as Labeled injection internal standard } \\
\hline 6 & BDE154 & ${ }^{13} \mathrm{C}_{12}-\mathrm{BDE}-154$ & 30.76 & $29.86-31.06$ & 16 & 1 & 4 \\
\hline 6 & BDE153 & ${ }^{13} \mathrm{C}_{12}-\mathrm{BDE}-153$ & 33.02 & $32.23-33.37$ & 18 & 1 & 4 \\
\hline 6 & BDE138 & ${ }^{13} \mathrm{C}_{12}-\mathrm{BDE}-153$ & 35.81 & $35.02-36.20$ & 20 & 2.5 & 10 \\
\hline 7 & BDE183 & ${ }^{13} \mathrm{C}_{12}$-BDE-183 & 39.00 & $38.22-39.33$ & 22 & 2.5 & 10 \\
\hline 7 & BDE190 & ${ }^{13} \mathrm{C}_{12}-\mathrm{BDE}-183$ & 42.19 & $41.46-42.57$ & 23 & 5 & 20 \\
\hline \multicolumn{8}{|c|}{ Labeled compounds } \\
\hline 3 & ${ }^{13} \mathrm{C}_{12}$-BDE-28 & ${ }^{13} \mathrm{C}_{12}$-BDE-77 & 14.91 & $14.21-15.43$ & 3 & - & - \\
\hline 4 & ${ }^{13} \mathrm{C}_{12}$-BDE-47 & ${ }^{13} \mathrm{C}_{12}$-BDE-77 & 20.38 & $19.68-20.87$ & 7 & - & - \\
\hline 5 & ${ }^{13} \mathrm{C}_{12}$-BDE-100 & ${ }^{13} \mathrm{C}_{12}$-BDE-77 & 25.05 & $24.21-25.55$ & 10 & - & - \\
\hline 5 & ${ }^{13} \mathrm{C}_{12}$-BDE-99 & ${ }^{13} \mathrm{C}_{12}$-BDE-77 & 26.67 & $25.93-27.14$ & 12 & - & - \\
\hline 6 & ${ }^{13} \mathrm{C}_{12}-\mathrm{BDE}-154$ & ${ }^{13} \mathrm{C}_{12}$-BDE-138 & 30.70 & $29.82-31.05$ & 15 & - & - \\
\hline 6 & ${ }^{13} \mathrm{C}_{12}$-BDE-153 & ${ }^{13} \mathrm{C}_{12}-\mathrm{BDE}-138$ & 33.00 & $32.20-33.35$ & 17 & - & - \\
\hline 7 & ${ }^{13} \mathrm{C}_{12}$-BDE-183 & ${ }^{13} \mathrm{C}_{12}$-BDE-138 & 38.99 & 38.18 - 39.35 & 21 & - & - \\
\hline \multicolumn{8}{|c|}{ Labeled injection internal standards } \\
\hline 4 & ${ }^{13} \mathrm{C}_{12}-\mathrm{BDE}-77$ & ${ }^{13} \mathrm{C}_{12}$-BDE-77 & 22.88 & 22.17 - 23.37 & 9 & - & - \\
\hline 6 & ${ }^{13} \mathrm{C}_{12}$-BDE-138 & ${ }^{13} \mathrm{C}_{12}$-BDE-138 & 35.80 & $35.00-36.25$ & 19 & - & - \\
\hline
\end{tabular}

The transverse line was indicated no data.

repeated analysis of the spiking and real samples, the guideline ranges for the deviation of the experimentally determined recovery corrected mean mass fraction from the spiking value must meet the requirements of the European Union document 2002/657/EC: Commission Decision of 12 August 2002 implementing Council Directive 96/23/EC concerning the performance of analytical methods and the interpretation of results. In addition, the recovery efficiency of all MBDE-MXFS by MBDE-MXFR shall be $60 \%$ or better.

\section{Results and Discussion}

\subsection{Analysis Method Development}

The method to simultaneous determine thirteen PBDEs in channel catfish and fish feeds samples was principally described by two methods as indicated above, but some important steps and crucial parameters were modified and intensified in this study. The main aspects regarding sample extraction and cleanup for sample preparations were intensified during the development of the method used.

Firstly, for sample extraction, PBDEs only fish samples were analyzed, and five to $10 \mathrm{~g}$ of the sample (wet weight) were homogenized with hydromatrix and extracted by PLE [26]. In contrast to the described method [26], the extraction in detail in the present study was reported to ensure the experimental feasibility. Moreover, new sample species such as fish feeds were applied in this study, and for the first time analysis method of PBDEs in fish feeds by isotopic dilution GC-MS was established in this paper. Three factors, lipid contents of 
fish feeds, feasibility of filtration with a $0.22 \mu \mathrm{m}$ membrane and $2.0 \mathrm{~mL}$ of sample injection volume subjected to multi-layer silica column chromatography during the sample preparation and cleanup, were carefully taken into consideration, and $2.5 \mathrm{~g}$ of fish feeds were chosen.

Next, multi-layer silica cleanup for the removals of acid compounds, basic compounds, sulfur and sulfur-containing molecules and small amounts of water was a very important step for determination of PBDEs in abiotic samples [27]. It was also considered that elution solvents and their compositions were most important factor for PBDEs in the study. Elution solvents and their compositions were modified in contrast to the ISO method [27]. For elution, $50 \mathrm{~mL}$ of cyclohexane was firstly used to ensure that all impurities could be well adsorbed in the silica, and cyclohexane eluent need be collected because a small amount of PBDEs were also eluted down. Then PBDEs were completely eluted by $50 \mathrm{~mL}$ of mixed solvent of cyclohexane and DCM. The volume ratio of cyclohexane and DCM were optimized according to the following method, involving four groups of experiments.

One milliliter of the mixed standard solution (the concentration of BDE17, BDE28, BDE47, BDE66, BDE71, BDE85, BDE99, BDE100, BDE138, BDE153, BDE154, BDE183 and BDE190 were $100 \mathrm{ng} \cdot \mathrm{mL}^{-1}$, respectively and the concentrations of ${ }^{13} \mathrm{C}_{12}$-labelled PBDEs 28, 47, 99, 100, 154, 153 and 183 were $100 \mathrm{ng} \cdot \mathrm{mL}^{-1}$, respectively) was subjected to four multi-layer silica columns, respectively. Four $50 \mathrm{~mL}$ of cyclohexane was firstly used to elute in four multi-layer silica columns, then $50 \mathrm{~mL}$ of cyclohexane: DCM (4:1), $50 \mathrm{~mL}$ of cyclohexane: DCM (7:3), $50 \mathrm{~mL}$ of cyclohexane: DCM (3:2) and $50 \mathrm{~mL}$ of cyclohexane: DCM (1:1), were respectively used to elute in four multi-layer silica columns. The flow rate is $2.5 \mathrm{~mL} \cdot \mathrm{min}^{-1}$. The next experiments were conducted according to the section 2 . The results showed the recoveries of all these compounds were most excellent by elution of $50 \mathrm{~mL}$ of cyclohexane: DCM (1:1). Similarly, the blank samples of channel catfish and fish feeds spiked at the same level as above mixed working standard were prepared prior to sample extractions, and the sample extractions were carried out according to the section 2. The sample cleanup of multi-layer silica column and following experiments were conducted according to the above method for the mixed working standard. It was also interesting that the recoveries of all these compounds were also most excellent by elution of $50 \mathrm{~mL}$ of cyclohexane: DCM (1:1). Moreover, the fractions collected were clean and contained little impurity, which indicated the impurity removal was successful. Therefore, the cleanup procedure that $50 \mathrm{~mL}$ of cyclohexane was used, and followed by $50 \mathrm{~mL}$ of cyclohexane: DCM (1:1) was chose.

Finally, GC and MS conditions were also very important factors for determinations of PBDEs, including ${ }^{13} \mathrm{C}_{12}$-labelled PBDEs. For MS acquisition, qualitative and quantitative analysis were performed using SIM. Table 1 provided further information optimized for these parameters, especially about quantitation reference for thirteen PBDEs, ensuring the operability of quantitation analysis. GC conditions were also optimized, including temperature programmed conditions and separation column. Temperature programmed conditions were optimized to ensure excellent separation efficiency of PBDEs and ${ }^{13} \mathrm{C}_{12}$-labelled PBDEs. Different separation columns were selected and compared to gain a more suitable separation effect, ensuring excellent experiment results.

\subsection{Calibration Curves, Limits of Quantitation and Recovery Rates}

Seven mixed series working standards of PBDEs at concentrations ranging from 5 to $250 \mathrm{ng} \cdot \mathrm{mL}^{-1}$ were prepared by dilution of standard stock solutions in iso-octane. In addition, appropriate amounts of the surrogate and syringe standard solutions were added to the calibration solutions to obtain a concentration of $100 \mathrm{ng} \cdot \mathrm{mL}^{-1}$ of each ${ }^{13} \mathrm{C}_{12}$-labelled PBDE congeners. Linear calibration curves for PBDEs by isotopic dilution and internal standard method were obtained with a $\gamma 2$ correlation coefficient of more than 0.99 . The linearity was checked by calculating the standard deviation of the average of response factors (peak area ratios divided by the corresponding analyte concentration ratios of all standards), which was $<15 \%$ assuming a linear response.

The limit of quantitation (LOQ), defined as the concentration of analyte which yielded a peak-to-peak signal-to-noise ratio of at least 10:1, was calculated by running a series of 10 blank extracts. Two blank extracts, channel catfish and fish feeds were analyzed. The detailed information for LOQ of channel catfish and fish feeds was presented in Table 2.

Spike recoveries of PBDEs in these productions were studied. Table 3 provided further information. Average recoveries and standard deviation (SD) of all concentrations analyzed triple samples met the requirements of the European Union document 2002/657/EC: Commission Decision of 12 August 2002 implementing Council Di- 
Table 3. Average recoveries and standard deviation of PBDEs in channel catfish and fish feeds (\%R $\pm \mathrm{SD}, \mathrm{n}=3)\left(\mu \mathrm{g} \cdot \mathrm{kg}^{-1}\right.$ wet weight).

\begin{tabular}{|c|c|c|c|c|c|c|c|c|}
\hline \multirow{2}{*}{ Br No. } & \multirow{2}{*}{ Compound } & \multirow{2}{*}{$\begin{array}{l}\text { Quantitation } \\
\text { reference }\end{array}$} & \multicolumn{3}{|c|}{ Recoveries from spiked channel catfish (\%) } & \multicolumn{3}{|c|}{ Recoveries from spiked fish feeds (\%) } \\
\hline & & & 2.5 & 10 & 25 & 10 & 40 & 100 \\
\hline \multicolumn{9}{|c|}{ Compounds using ${ }^{13} \mathrm{C}_{12}$-BDE-77 as Labeled injection internal standard } \\
\hline 3 & BDE17 & ${ }^{13} \mathrm{C}_{12}-\mathrm{BDE}-28$ & $92 \pm 7$ & $92 \pm 5$ & $96 \pm 6$ & $92 \pm 5$ & $103 \pm 5$ & $102 \pm 6$ \\
\hline 3 & BDE28 & ${ }^{13} \mathrm{C}_{12}-\mathrm{BDE}-28$ & $87 \pm 7$ & $96 \pm 5$ & $94 \pm 8$ & $96 \pm 5$ & $101 \pm 9$ & $98 \pm 9$ \\
\hline 4 & BDE71 & ${ }^{13} \mathrm{C}_{12}$-BDE-47 & $74 \pm 6$ & $89 \pm 10$ & $95 \pm 5$ & $84 \pm 6$ & $101 \pm 9$ & $101 \pm 7$ \\
\hline 4 & BDE47 & ${ }^{13} \mathrm{C}_{12}$-BDE-47 & $87 \pm 5$ & $91 \pm 7$ & $96 \pm 10$ & $93 \pm 7$ & $99 \pm 6$ & $101 \pm 7$ \\
\hline 4 & BDE66 & ${ }^{13} \mathrm{C}_{12}$-BDE-47 & $78 \pm 9$ & $86 \pm 5$ & $93 \pm 12$ & $92 \pm 10$ & $101 \pm 9$ & $100 \pm 9$ \\
\hline 5 & BDE100 & ${ }^{13} \mathrm{C}_{12}-\mathrm{BDE}-100$ & $82 \pm 12$ & $83 \pm 6$ & $95 \pm 5$ & $91 \pm 8$ & $103 \pm 8$ & $103 \pm 8$ \\
\hline 5 & BDE99 & ${ }^{13} \mathrm{C}_{12}$-BDE-99 & $81 \pm 14$ & $85 \pm 7$ & $94 \pm 9$ & $90 \pm 11$ & $96 \pm 7$ & $97 \pm 5$ \\
\hline 5 & BDE85 & ${ }^{13} \mathrm{C}_{12}$-BDE-99 & $78 \pm 16$ & $85 \pm 6$ & $87 \pm 5$ & $87 \pm 5$ & $95 \pm 7$ & $101 \pm 6$ \\
\hline \multicolumn{9}{|c|}{ Compounds using ${ }^{13} \mathrm{C}_{12}$-BDE-138 as Labeled injection internal standard } \\
\hline 6 & BDE154 & ${ }^{13} \mathrm{C}_{12}-\mathrm{BDE}-154$ & $74 \pm 7$ & $84 \pm 6$ & $89 \pm 7$ & $87 \pm 8$ & $96 \pm 10$ & $96 \pm 11$ \\
\hline 6 & BDE153 & ${ }^{13} \mathrm{C}_{12}-\mathrm{BDE}-153$ & $75 \pm 8$ & $82 \pm 4$ & $90 \pm 9$ & $88 \pm 9$ & $90 \pm 7$ & $96 \pm 10$ \\
\hline 6 & BDE138 & ${ }^{13} \mathrm{C}_{12}-\mathrm{BDE}-153$ & $75 \pm 8$ & $82 \pm 4$ & $85 \pm 7$ & $85 \pm 7$ & $87 \pm 6$ & $94 \pm 7$ \\
\hline 7 & BDE183 & ${ }^{13} \mathrm{C}_{12}-\mathrm{BDE}-183$ & $83 \pm 8$ & $83 \pm 3$ & $85 \pm 5$ & $85 \pm 4$ & $97 \pm 11$ & $91 \pm 7$ \\
\hline 7 & BDE190 & ${ }^{13} \mathrm{C}_{12}-\mathrm{BDE}-183$ & - & $80 \pm 13$ & $84 \pm 5$ & - & $91 \pm 9$ & $90 \pm 5$ \\
\hline
\end{tabular}

The transverse line was indicated no data because the spiked amount was below LOQ.

rective 96/23/EC concerning the performance of analytical methods and the interpretation of results. In addition, the recovery efficiency of all MBDE-MXFS by MBDE-MXFR was more than $80 \%$.

\subsection{Analysis of Channel Catfish and Fish Feeds}

GC-MS chromatogram of a mixed standard solution of PBDEs and ${ }^{13} \mathrm{C}_{12}$-labelled PBDEs (the concentration of BDE17, BDE28, BDE47, BDE66, BDE71, BDE85, BDE99, BDE100, BDE138, BDE153, BDE154, BDE183 and BDE190 were $100 \mathrm{ng} \cdot \mathrm{mL}^{-1}$, respectively, the concentrations of ${ }^{13} \mathrm{C}_{12}$-labelled PBDEs 28, 47, 99, 100, 154, 153 and 183 as surrogate internal standard were $100 \mathrm{ng} \cdot \mathrm{mL}^{-1}$, respectively, and the concentration of ${ }^{13} \mathrm{C}_{12}$-labelled PBDEs 77 and 138 as syringe standard were $100 \mathrm{ng} \cdot \mathrm{mL}^{-1}$, respectively), was shown in Figure 1.

Based on the established methods, a large number of channel catfish and fish feeds were tested. PBDEs emerged in 10 of 180 channel catfish and 13 of 115 fish feeds. Table 4 and Table 5 provided further information.

It can be seen from Table 4 and Table 5 that the dominant PBDEs homologues were PBDE-28, PBDE-47, PBDE-100, PBDE-99, PBDE-154, PBDE-153 and PBDE-183 in thirteen fish feeds samples and ten channel catfish samples. In addition, seven PBDEs homologue detection rates in fishery products show that detection rates of PBDE-28, PBDE-47, PBDE-100, PBDE-99, PBDE-154, PBDE-153 and PBDE-183 were respectively 1.74\%, 7.83\%, 4.35\%, 5.22\%, 3.48\%, 2.61\% and 2.61\% in fish feeds, and detection rates of PBDE-28, PBDE-47, PBDE-100, PBDE-99, PBDE-154, PBDE-153 and PBDE-183 were respectively 1.11\%, 3.89\%, 2.22\%, 1.67\%, $1.11 \%, 1.11 \%$ and $1.11 \%$ in channel catfish. The results suggest that fish feeds contaminated with PBDEs may cause PBDEs residual in channel catfish through biological shift.

\subsection{Biological Shift of PBDEs in Fishery Products}

In the past, Eljarrat et al. determined PBDEs of bleak fish (Alburnus alburnus) collected from three places along the Spanish River Cinca, a tributary of Ebro River, and four different PBDE congeners (PBDE-47, PBDE-153, PBDE-154 and PBDE-183) were found at levels ranging from not detected (nd) to $573 \mathrm{ng} \cdot \mathrm{g}^{-1}$ wet weight for total PBDEs [28]. Levels of PBDE were determined in whitefish (Coregonus sp.) from eight Swiss lakes and in rainbow trout (Oncorhynchus mykiss) from four Swiss fish farms. PBDE concentrations (sum of PBDE congeners PBDE-28, PBDE-47, PBDE-99, PBDE-100, PBDE-153, PBDE-154 and PBDE-183) in filet from whitefish between 36 and $165 \mathrm{ng} \cdot \mathrm{g}^{-1}$ lipid weight (lw) were found. PBDE contents in filet from farmed rainbow trout were significantly lower than in wild whitefish (12 - $\left.24 \mathrm{ng} \cdot \mathrm{g}^{-1} \mathrm{lw}\right)$ [29]. PBDEs were identified in fish collected from 
the Detroit River and Des Plaines Rivers. In the Detroit River fish, carp and large mouth bass, the congener patterns were dominated by PBDE-47, however, in Des Plaines River carp the dominant isomers were PBDE-181 and PBDE-183 and lesser amounts of PBDE-190, PBDE-154 and PBDE-153 [30].

Recently, it was reported that PBDEs was present in fish samples at relatively high levels [31] [32]. For ex-

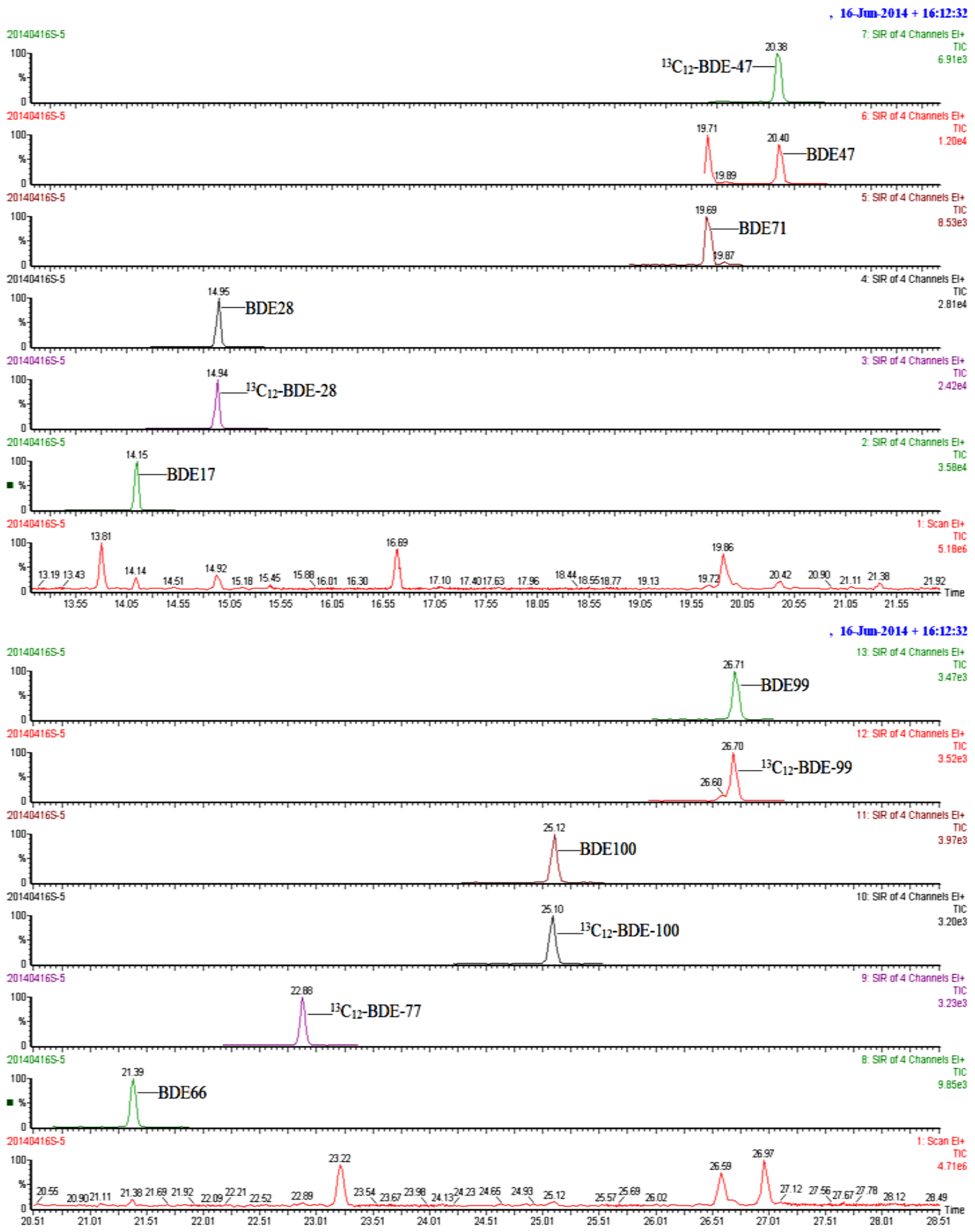




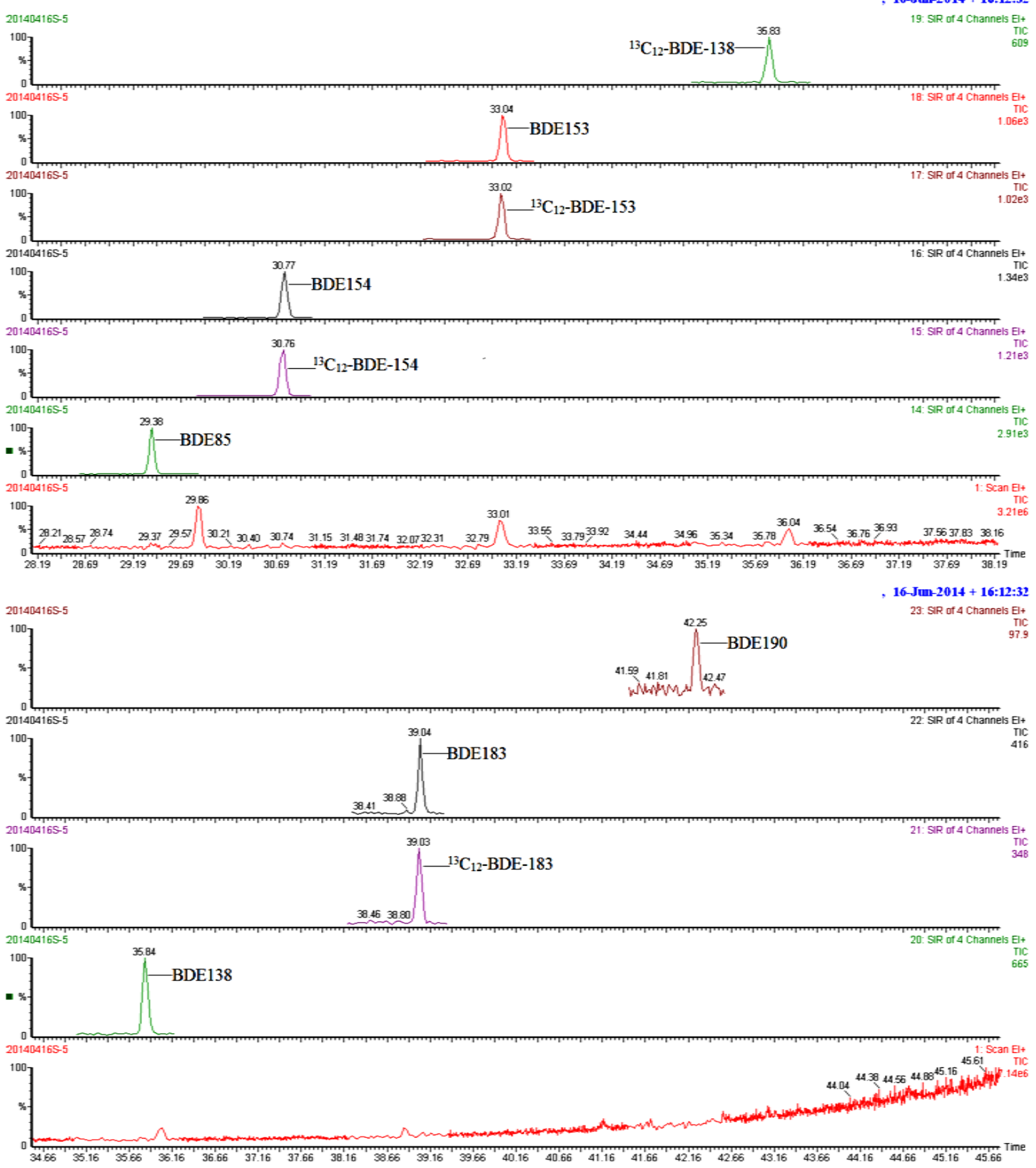

Figure 1. GC-MS chromatogram of a mixed standard solution of PBDEs (the concentration of BDE17, BDE28, BDE47, BDE66, BDE71, BDE85, BDE99, BDE100, BDE138, BDE153, BDE154, BDE183 and BDE190 were $100 \mathrm{ng} \cdot \mathrm{mL}^{-1}$, respectively, the concentrations of ${ }^{13} \mathrm{C}_{12}$-labelled PBDEs $28,47,99,100,154,153$ and 183 were $100 \mathrm{ng} \cdot \mathrm{mL}^{-1}$, respectively, and the concentration of ${ }^{13} \mathrm{C}_{12}$-labelled PBDEs 77 and 138 were $100 \mathrm{ng} \cdot \mathrm{mL}^{-1}$, respectively).

ample, in all fish samples from the Mediterranean Sea, PBDE-47 was the predominant congener followed by PBDE-99 and PBDE-100, and other three congeners, PBDE-153, PBDE-154 and PBDE-183 were detected [31]. PBDEs were detected in mullet (Mugil cephalus) and sea bass (Dicentrarchus labrax) from the Bizerte Lagoon and the Mediterranean Sea. The PBDE mean concentrations in fish from Bizerte Lagoon were 45.3 and $96.2 \mathrm{ng} \cdot \mathrm{g}^{-1}$ lw respectively in mullet and sea bass, while the concentrations of these compounds in mullet and sea bass 
Table 4. Contents of PBDEs in thirteen fish feeds samples $\left(\mu \mathrm{g} \cdot \mathrm{kg}^{-1}\right.$ wet weight).

\begin{tabular}{|c|c|c|c|c|c|c|c|c|c|c|c|c|c|c|}
\hline \multirow{2}{*}{ Br No. } & \multirow{2}{*}{ Compound } & \multicolumn{13}{|c|}{ Fish feeds } \\
\hline & & $\# 1$ & $\# 2$ & $\# 3$ & $\# 4$ & $\# 5$ & $\# 6$ & $\# 7$ & $\# 8$ & $\# 9$ & $\# 10$ & $\# 11$ & $\# 12$ & $\# 13$ \\
\hline 3 & BDE17 & ND & ND & ND & ND & ND & ND & ND & ND & ND & ND & ND & ND & ND \\
\hline 3 & BDE28 & ND & ND & ND & 4.14 & ND & ND & ND & ND & ND & 4.62 & ND & ND & ND \\
\hline 4 & BDE71 & ND & ND & ND & ND & ND & ND & ND & ND & ND & ND & ND & ND & ND \\
\hline 4 & BDE47 & 6.11 & ND & 4.39 & 5.75 & 9.38 & 5.42 & 9.45 & ND & ND & 7.84 & 5.16 & ND & 4.12 \\
\hline 4 & BDE66 & ND & ND & ND & ND & ND & ND & ND & ND & ND & ND & ND & ND & ND \\
\hline 5 & BDE100 & 12.17 & ND & ND & 9.84 & 8.69 & ND & 10.72 & ND & ND & ND & 10.67 & ND & ND \\
\hline 5 & BDE99 & 9.78 & ND & ND & 11.47 & 8.71 & ND & 12.63 & ND & ND & ND & 8.14 & 5.37 & ND \\
\hline 5 & BDE85 & ND & ND & ND & ND & ND & ND & ND & ND & ND & ND & ND & ND & ND \\
\hline 6 & BDE154 & ND & 10.07 & ND & ND & ND & ND & ND & 7.78 & 6.62 & ND & ND & ND & 7.27 \\
\hline 6 & BDE153 & ND & 12.31 & ND & ND & ND & ND & 5.41 & 6.47 & ND & ND & ND & ND & ND \\
\hline 6 & BDE138 & ND & ND & ND & ND & ND & ND & ND & ND & ND & ND & ND & ND & ND \\
\hline 7 & BDE183 & ND & 23.65 & ND & ND & ND & ND & ND & 16.61 & 14.12 & ND & ND & ND & ND \\
\hline 7 & BDE190 & ND & ND & ND & ND & ND & ND & ND & ND & ND & ND & ND & ND & ND \\
\hline- & $\sum$ PBDEs & 28.06 & 46.03 & 4.39 & 31.20 & 26.78 & 5.42 & 38.21 & 30.86 & 20.74 & 12.46 & 23.97 & 5.37 & 11.39 \\
\hline
\end{tabular}

ND, lower than LOQ.

Table 5. Contents of PBDEs in ten channel catfish samples ( $\mu \mathrm{g} \cdot \mathrm{kg}^{-1}$ wet weight).

\begin{tabular}{|c|c|c|c|c|c|c|c|c|c|c|c|}
\hline \multirow{2}{*}{ Br No. } & \multirow{2}{*}{ Compound } & \multicolumn{10}{|c|}{ Channel catfish } \\
\hline & & $\# 1$ & $\# 2$ & $\# 3$ & $\# 4$ & $\# 5$ & $\# 6$ & $\# 5$ & $\# 8$ & $\# 9$ & $\# 10$ \\
\hline 3 & BDE17 & ND & ND & ND & ND & ND & ND & ND & ND & ND & ND \\
\hline 3 & BDE28 & ND & ND & 2.35 & ND & 1.75 & ND & ND & ND & ND & ND \\
\hline 4 & BDE71 & ND & ND & ND & ND & ND & ND & ND & ND & ND & ND \\
\hline 4 & BDE47 & 2.73 & 2.54 & 4.76 & 4.52 & 2.45 & ND & ND & 2.81 & 5.04 & ND \\
\hline 4 & BDE66 & ND & ND & ND & ND & ND & ND & ND & ND & ND & ND \\
\hline 5 & BDE100 & 4.98 & 3.41 & 4.20 & ND & ND & ND & 3.04 & ND & ND & ND \\
\hline 5 & BDE99 & 4.25 & ND & ND & ND & ND & ND & 5.18 & 5.04 & ND & ND \\
\hline 5 & BDE85 & ND & ND & ND & ND & ND & ND & ND & ND & ND & ND \\
\hline 6 & BDE154 & ND & 2.95 & ND & ND & ND & 3.54 & ND & ND & ND & ND \\
\hline 6 & BDE153 & ND & 3.77 & ND & ND & ND & ND & ND & ND & ND & 3.28 \\
\hline 6 & BDE138 & ND & ND & ND & ND & ND & ND & ND & ND & ND & ND \\
\hline 7 & BDE183 & ND & ND & ND & ND & ND & 6.34 & ND & ND & ND & 6.14 \\
\hline 7 & BDE190 & ND & ND & ND & ND & ND & ND & ND & ND & ND & ND \\
\hline- & $\sum$ PBDEs & 11.96 & 12.67 & 11.31 & 4.52 & 4.20 & 9.88 & 8.22 & 7.85 & 5.04 & 9.42 \\
\hline
\end{tabular}

ND, lower than LOQ.

from Mediterranean Sea were 7.80 and $27.9 \mathrm{ng} \cdot \mathrm{g}^{-1} \mathrm{lw}$ respectively. The seven predominant congeners were PBDE-28, PBDE-47, PBDE-99, PBDE-100, PBDE-153, PBDE-154 and PBDE-183 [32].

On the basis of those reported results, it is reasonable that the contamination of PBDE-28, PBDE-47, PBDE-100, PBDE-99, PBDE-154, PBDE-153 and PBDE-183 were found in channel catfish and fish feeds from China possibly due to their selective residues and biological enrichment in biology samples. The contamination of PBDEs in aquatic products can potentially result in a health risk to residents.

In order to discover whether there is a transfer for PBDEs between fishery products, the correlation of PBDEs between matching channel catfish and fish feeds were analyzed. The results indicated that there was significant correlation in PBDEs between matching channel catfish and fish feeds $\left(\mathrm{R}^{2}=0.742, \mathrm{P}<0.001, \mathrm{n}=30\right.$ ) (Figure 2), suggesting that fish feeds contaminated with PBDEs possibly resulted in PBDEs residual in channel catfish through biological transfer.

Considering the links between the safety of fish feeds and the safety of channel catfish, contaminations and 


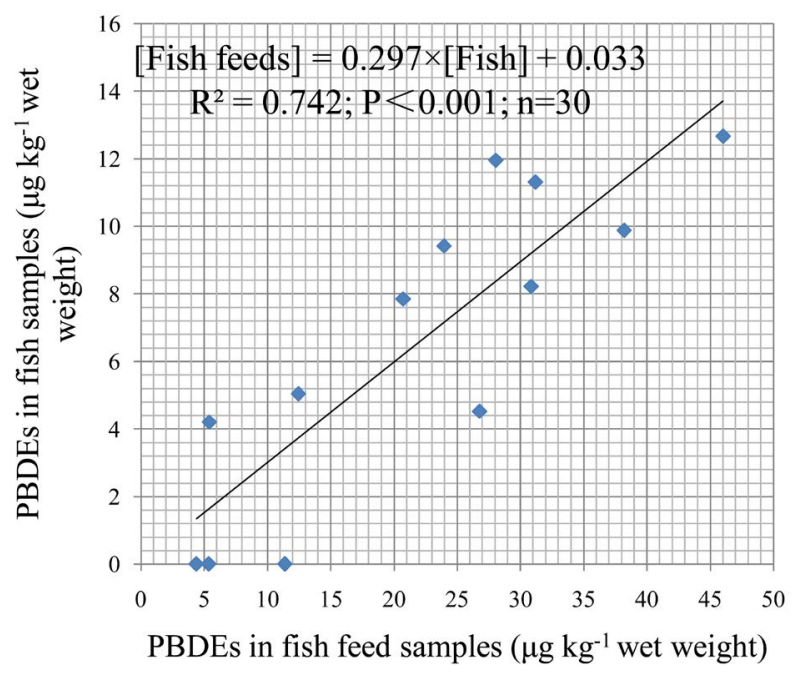

Figure 2. The correlation between PBDEs in fish samples and fish feed samples.

causes of PBDEs in channel catfish and fish feeds, including other factors such as water and sediment for biological shift of PBDEs in fishery products still need to be investigated in the future.

\section{Conclusion}

A fast isotopic dilution GC-MS method was firstly developed to simultaneously determine thirteen PBDEs in channel catfish and fish feeds in this study, and especially for the first time PBDEs in fish feeds. Pressurized liquid extraction and multi-layer silica gel column chromatography cleanup were used. Some important steps and crucial parameters in sample extraction, sample cleanup and quantitation ways of analytes were optimized to ensure the experimental and calculative feasibility. The limits of quantitation, repeatability and accuracy of the whole method were studied and achieved. Using the established methods, PBDEs emerged in 10 of 180 channel catfish and 13 of 115 fish feeds. The bioaccumulative characteristics and biological transfer of PBDEs in fishery products indicate there was significant correlation in PBDEs between matching channel catfish and fish feeds, suggesting that fish feeds contaminated with PBDEs possibly resulted in PBDEs residual in channel catfish through biological transfer.

\section{Acknowledgements}

This study was supported by the Research Projects of General Administration of Quality Supervision, Inspection and Quarantine of P.R.C (2013IK158 and 2014IK106) and Special Fund for Quality inspection Research in the Public Interest, China (201410059).

\section{References}

[1] De Wit, C.A. (2002) An Overview of Brominated Flame Retardants in the Environment. Chemosphere, 46, 583-624. http://dx.doi.org/10.1016/S0045-6535(01)00225-9

[2] Watanabe, I. and Sakai, S.I. (2003) Environmental Release and Behavior of Brominated Flame Retardants. Environment International, 29, 665-682. http://dx.doi.org/10.1016/S0160-4120(03)00123-5

[3] Alaee, M., Arias, P., Sjodin, A. and Bergman, A. (2003) An Overview of Commercially Used Brominated Flame Retardants, Their Applications, Their Use Patterns in Different Countries/Regions and Possible Modes of Release. Environment International, 29, 683-689. http://dx.doi.org/10.1016/s0160-4120(03)00121-1

[4] Alcock, R., Sweetman, A.J., Prevedouros, K. and Jones, K.C. (2003) Understanding Levels and Trends of BDE-47 in the UK and North America: An Assessment of Principal Reservoirs and Source Inputs. Environment International, 29, 691-698. http://dx.doi.org/10.1016/S0160-4120(03)00120-X

[5] Wilford, B.H., Harner, T., Zhu, J., Shoeib, M. and Jones, K.C. (2004) Passive Sampling Survey of Polybrominated Diphenyl Ether Flame Retardants in Indoor and Outdoor Air in Ottawa, Canada: Implications for Sources and Expo- 
sure. Environmental Science and Technology, 38, 5312-5318. http://dx.doi.org/10.1021/es049260x

[6] Stapleton, H.M., Dodder, N.G., Offenberg, J.H., Schantz, M.M. and Wise, S.A. (2005) Polybrominated Diphenyl Ethers in House Dust and clothes Dryer Lint. Environmental Science and Technology, 39, 925-931. http://dx.doi.org/10.1021/es0486824

[7] Kirkegaard, A., Bignert, A., Sellstrom, U., Olsson, M., Jansson, B. and de Wit, C.A. (2004) Polybrominated Diphenyl Ethers (PBDEs) and Their Methoxylated Derivates in Pike from Swedish Waters with Emphasis on Temporal Trends, 1967-2000. Environmental Pollution, 130, 187-198. http://dx.doi.org/10.1016/j.envpol.2003.12.011

[8] Meironyte, D., Noren, K. and Bergman, A. (1999) Analysis of Polybrominated Diphenyl Ethers in Swedish Human milk. A Time-Related Trend Study, 1992-1997. Journal of Toxicology and Environment Health A, 58, 329-341. http://dx.doi.org/10.1080/009841099157197

[9] Nordlof, U., Helander, B., Bignert, A. and Asplund, L. (2010) Levels of Brominated Flame Retardants and Methoxylated Polybrominated Diphenyl Ethers in Eggs of White-Tailed Sea Eagles Breeding in Different Regions of Sweden. Science of the Total Environment, 409, 238-246. http://dx.doi.org/10.1016/j.scitotenv.2010.09.042

[10] Rotander, A., van Bavel, B., Riget, F., Auðunsson, G.A., Polder, A., Gabrielsen, G.W., Víkingsson, G., Mikkelsen, B. and Dam, M. (2012) Methoxylated Polybrominated Diphenyl Ethers (MeO-PBDEs) Are Major Contributors to the Persistent Organobromine Load in Sub-Arctic and Arctic Marine Mammals, 1986-2009. Science of the Total Environment, 416, 482-489. http://dx.doi.org/10.1016/j.scitotenv.2011.12.010

[11] Darnerud, P.O., Eriksen, G.S., Jóhannesson, T., Larsen, P.B. and Viluksela, M. (2001) Polybrominated Diphenyl Ethers: Occurrence, Dietary Exposure and Toxicology. Environmental Health Perspectives, 109, 49-68. http://dx.doi.org/10.2307/3434846

[12] Kuriyama, S.N., Talsness, C.E., Grote, K. and Chahoud, I. (2005) Developmental Exposure to Low-Dose PBDE-99: Effects on Male Fertility and Neurobehavior in Rat Offspring. Environmental Health Perspectives, 113, 149-154. http://dx.doi.org/10.1289/ehp.7421

[13] Eriksson, P., Jakobsson, E. and Fredriksson, A. (2001) Brominated Flame Retardants: A Novel Class of Developmental Neurotoxicants in Our Environment? Environmental Health Perspectives, 109, 903-908.

[14] Viberg, H., Fredriksson, A. and Eriksson, P. (2002) Neonatal Exposure to the Brominated Flame Retardant 2,2', 4,4', 5-Pentabromodiphenyl Ether Causes Altered Susceptibility in the Cholinergic Transmitter System in the Adult Mouse. Toxicological Sciences, 67, 104-107. http://dx.doi.org/10.1093/toxsci/67.1.104

[15] Viberg, H., Fredriksson, A. and Eriksson, P. (2003) Neonatal Exposure to Polybrominated Diphenyl Ether (PBDE 153) Disrupts Spontaneous Behaviour, Impairs Learning and Memeory, and Decreases Hippocampal Cholinergic Receptors in Adult Mice. Toxicology and Applied Pharmacology, 192, 95-106. http://dx.doi.org/10.1016/S0041-008X(03)00217-5

[16] Zhou, T., Taylor, M.M., DeVito, M.J. and Crofton, K.M. (2002) Developmental Exposure to Brominated Diphenyl Ethers Results in Thyroid Hormone Disruption. Toxicological Sciences, 66, 105-116. http://dx.doi.org/10.1093/toxsci/66.1.105

[17] Branchi, I., Alleva, E. and Costa, L.G. (2002) Effects of Perinatal Exposure to a Polybrominated Diphenyl Ether (PBDE 99) on Mouse Neurobehavioural Development. Neurotoxicology, 23, 375-384. http://dx.doi.org/10.1016/S0161-813X(02)00078-5

[18] Branchi, I., Capone, F., Alleva, E. and Costa, L.G. (2003) Polybrominated Diphenyl Ethers: Neurobehavioral Effects Following Developmental Exposure. NeuroToxicology, 24, 449-462. http://dx.doi.org/10.1016/S0161-813X(03)00020-2

[19] Reistad, T., Fonnum, F. and Mariussen, E. (2006) Neurotoxicity of the Pentabrominated Diphenyl Ether Mixture, DE71, and Hexabromocyclododecane (HBCD) in Rat Cerebellar Granule Cells in Vitro. Archives of Toxicology, 80, 785796. http://dx.doi.org/10.1007/s00204-006-0099-8

[20] Madia, F., Giordano, G., Fattori, V., Vitalone, A., Branchi, I., Capone, F. and Costa, L.G. (2004) Differential in Vitro Neurotoxicity of the Flame Retardant PBDE-99 and of the PCB Aroclor 1254 in Human Astrocytoma Cells. Toxicology Letters, 154, 11-21. http://dx.doi.org/10.1016/j.toxlet.2004.06.013

[21] Hu, X.Z., Xu, Y., Hu, D.C., Hui, Y. and Yang, F.X. (2007) Apoptosis Induction on Human Hepatoma Cells Hep G2 of Decabrominated Diphenyl Ether (PBDE-209) Toxicology Letters, 171, 19-28. http://dx.doi.org/10.1016/j.toxlet.2007.04.002

[22] Hu, X.Z., Hu, D.C. and Xu, Y. (2009) Effects of Tetrabrominated Diphenyl Ether and Hexabromocyclododecanes in Single and Complex Exposure to Hepatoma HepG2 Cells. Environmental Toxicology and Pharmacology, 27, 327-337. http://dx.doi.org/10.1016/j.etap.2008.11.014

[23] Hu, X.Z., Hu, D.C., Song, Q., Li, J., Wang, P. and Guo, S.F. (2011) Analysis and Occurrences of Perfluorinated Compounds in Agricultural and Aquatic Products and Water from China. Journal of Liquid Chromatography and Related 
Technologies, 34, 2196-2210. http://dx.doi.org/10.1080/10826076.2011.585549

[24] Hu, X.Z., Hu, D.C., Song, Q., Li, J. and Wang, P. (2011) Determinations of Hexabromocyclododecane (HBCD) Isomers in Channel Catfish, Crayfish, Hen Eggs and Fish Feeds from China by Isotopic Dilution LC-MS/MS. Chemosphere, 82, 698-707. http://dx.doi.org/10.1016/j.chemosphere.2010.10.096

[25] Hu, X.Z., Xu, Y. and Yediler, A. (2007) Determinations of Residual Furazolidone and Its Metabolite, 3-Amino-2oxazolidinone (AOZ), in Fish Feeds by HPLC-UV and LC-MS/MS, Respectively. Journal of Agricultural and Food Chemistry, 55, 1144-1149. http://dx.doi.org/10.1021/jf062902a

[26] Lacorte, S., Ikonomou, M.G. and Fischer, M. (2010) A Comprehensive Gas Chromatography Coupled to High Resolution Mass Spectrometry Based Method for the Determination of Polybrominated Diphenyl Ethers and Their Hydroxylated and Methoxylated Metabolites in Environmental Samples. Journal of Chromatography A, 1217, 337-347. http://dx.doi.org/10.1016/j.chroma.2009.11.024

[27] ISO 22032-2006 Water Quality-Determination of Selected Polybrominated Diphenyl Ethers in Sediment and Sewage Sludge-Method Using Extraction and Gas Chromatography/Mass Spectrometry.

[28] Eljarrat, E., de la Cal, A., Raldua, D., Duran, C. and Barcelo, D. (2005) Brominated Flame Retardants in Alburnus alburnus from Cinca River Basin (Spain). Environmental Pollution, 133, 501-508. http://dx.doi.org/10.1016/j.envpol.2004.06.017

[29] Zennegg, M., Kohler, M., Gerecke, A.C. and Schmid, P. (2003) Polybrominated Diphenyl Ethers in Whitefish from Swiss Lakes and Farmed Rainbow Trout. Chemosphere, 51, 545-553. http://dx.doi.org/10.1016/S0045-6535(03)00047-X

[30] Rice, C.P., Chernyak, S.M., Begnoche, L., Quintal, R. and Hickey, J. (2002) Comparisons of PBDE Composition and Concentration in Fish Collected from the Detroit River, MI and Des Plaines River, II. Chemosphere, 49, 731-737. http://dx.doi.org/10.1016/S0045-6535(02)00398-3

[31] Losada, S., Santos, F.J., Covaci, A. and Galceran, M.T. (2010) Gas Chromatography-Ion Trap Tandem Mass Spectrometry Method for the Analysis of Methoxylated Polybrominated Diphenyl Ethers in Fish. Journal of Chromatography A, 1217, 5253-5260. http://dx.doi.org/10.1016/j.chroma.2010.06.023

[32] Ameur, W.B., Hassine, S.B., Eljarrat, E., EI Megdiche, Y., Trabelsi, S., Hammami, B., Barceló, D. and Driss, M.R. (2011) Polybrominated Diphenyl Ethers and Their Methoxylated Analogs in Mullet (Mugil cephalus) and Sea Bass (Dicentrarchus labrax) from Bizerte Lagoon, Tunisia. Marine Environment Research, 72, 258-264.

http://dx.doi.org/10.1016/j.marenvres.2011.09.009. 
Scientific Research Publishing (SCIRP) is one of the largest Open Access journal publishers. It is currently publishing more than 200 open access, online, peer-reviewed journals covering a wide range of academic disciplines. SCIRP serves the worldwide academic communities and contributes to the progress and application of science with its publication.

Other selected journals from SCIRP are listed as below. Submit your manuscript to us via either submit@scirp.org or Online Submission Portal.
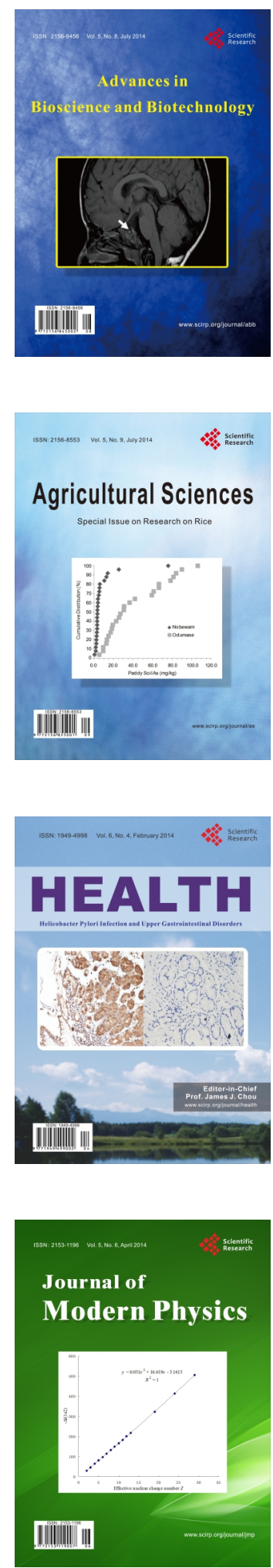
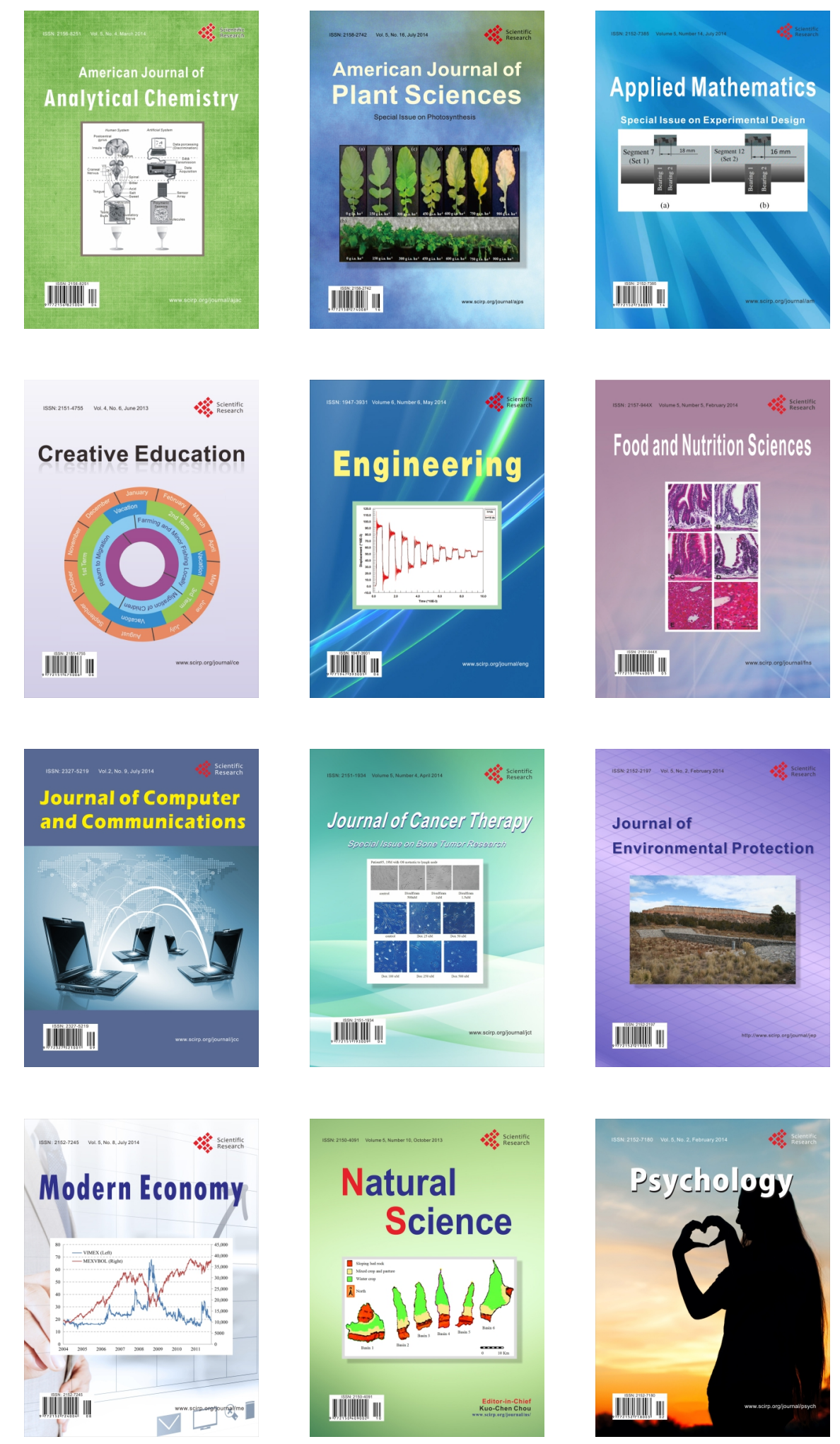